Jod-Jodkaliumlösung*), welcher die Fasern ganz bedecken soll. Nach 1-2 Minuten langer Einwirkung nimmt man die Lösung durch zweimaliges Abdrücken mit Filtrirpapier vollständig wieder fort, so dass keine Jodlösung sich mehr zwischeu den Fasern befindet. Das so mit Jodlösung behandelte, aus 4 Fasern bestehende Präparat wird nun mit einem Tropfen Schwefelsäure bedeckt, worauf man das Deckglas auflegt. Die Schwefelsäure muss man so weit verdünnen, dass sich bei dieser Behandlung Baumwolle, Flachs, Hanf schön rothviolett, Holzcellulose und gewöhnliche Strohcellulose rein blau oder graublau färben. Hat man sich die Schwefelsäure richtig eingestellt, so bietet die Unterscheidung der Papierfasern keine Schwierigkeiten.

Die Methode kann für die gewöhnlichen, weissen, besseren Papiere, welche, wie das deutsche und österreichische Fabrikat, fast nie Espartooder Maisfasern enthalten, ohne Weiteres angewendet werden und gibt in der Regel ganz sichere Ergebnisse. In diesen Papieren färben sich ausnahmslos Baumwolle, Hanf, Flachs, weissgebleichte Jute, Chinagras und Papiermaulbeerbaum rothviolett, Holz- und gewöhnliche Strohcellulose rein blau, Holzschliff und ungebleichte Jute dunkelgelb. Enthalten die Papiere Esparto- oder Maisfasern (welche leicht zu erkennen sind) so soll man etwas concentrirtere Schwefelsäure anwenden, oder eine kurze Vorbehandlung mit Salpetersäure geben.

Das Verfahren gilt nur für die Fasern in Feinpapieren. Rohfasem and Grob-Papiere, in welchen die Fasern nicht schon starke Bleichung erlitten haben, verhalten sich theilweise ganz anders.

\title{
Ein Verfahren zur quantitativen Bestimmung des Holzschliffes
} im Papier gründen R. Godeffroy und M. Coulon***) darauf, dass Cellulose, welche mit Wasser, Alkohol und Aether ausgekocht ist, beim Kochen mit verdünnter Goldchloridlösung letztere nicht reducirt, während Holzschliff stark reducirend wirkt. $100 \mathrm{~g}$ des letzteren (völlig getrocknet) schieden bei gleicher Behandlung 14,285 $g$ Gold ab.

Bei Untersuchung von Papieren wird die genau gewogene Probe zur Beseitigung der Leimung zuerst mit kaltem, dann mit siedendem Wasser und schliesslich zur Entfernung der Thonerde mit einer siedenden

*) Dieselbe muss so concentrirt sein, dass eine etwa $3 \mathrm{~cm}$ dicke Schicht rubinroth und dabei klar und durchsichtig erscheint.

**) Mittheil. d. technolog. Gewerbe-Museums zu Wien, durch Zeitschr. d. Allg. Oesterr. Apotheler-Vereines 27, 21. 
Lösung von Weinsäure in 80 procentigem Alkohol gewaschen, getrocknet, nun mit Alkohol and mit Aether ausgezogen und hierauf mit Goldchlorid behandelt.

Zur mechanisch-mikroskopischen Analyse von Futtermehlen führt Th. Ritter v. Weinzierl*) mit etwa $100 \mathrm{~g}$ der gut durchgemischten Probe folgende Arbeiten aus:

1. Die mechan ische Trennung der Bestandtheile nach deren Grösse durch Siebe**) von verschiedener Lochweite, und zwar $1,5 \mathrm{~mm}$, beziehungsweise $1 \mathrm{~mm}, 0,5 \mathrm{~mm}$ and $0,25 \mathrm{~mm}$, indem die Probe in einzelnen Portionen mittelst eines breiten, kurzen Borstenpinsels sorgfältig durchgebürstet wird.

Das vierte der auf diese Weise gewomnenen vier Producte gibt den Mehlgehalt, beziehungsweise Feinheitsgrad der Probe direct an. Ausserdem wird durch diese Trennung die weitere qualitative und quantitative Untersuchung wesentlich erleichtert.

2. Die Bestimmang der Echtheit der Ware und der Art der fremden Bestand theile. Es ist zweckmässig, diese Untersuchung erst nach der Beendigung der Siebarbeit vorzunehmen, weil oft einzelne fremde Bestandtheile schon mit freiem Auge im ersten oder zweiten Product sich erkennen lassen; für die Untersuchung des dritten Productes eignet sich am besten die vom Verfasser erfundene Stativlupe***). Wo es auf anatomische Merkmale ankommt, wie speciell bei der Echtheitsbestimmung von Kleien, verschiedenen Mehlen und dergleichen, muss natürlich mikroskopisch untersucht werden. Hierbei gelten

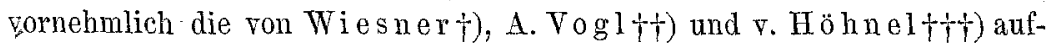
gefundenen und angegebenen anatomischen und physikalischen Kennzeichen verschiedener Mahlproducte.

*) Die qualitative und quantitative mechanisch-mikroskopische Analyse, eine neue Untersuchungsmethode der Mahlproducte auf deren Futterwerth und eventuelle Verfälschungen. Wien 1887; im Sonderabdruck ans der Zeitschrift für Nahrungsmitteluntersuchung und Hygiene vom Verfasser eingesandt.

**) Hierzu verwendet Verfasser die Nobbe'schen Samensiebe.

***) v. Weinzierl: „Eine neue Lupe für Samenuntersuchungen. Ztschrft. f. wissenschaftl. Mikroskopie, IV. Bd., 1. Heft, 1887.

†) J. Wiesner: "Die Rohstoffe des Pflanzenreiches.“ W. Engelmann, Leipzig 1873. Derselbe: Technische Mikroskopie. Wien 1867.

††) A. Vog 1: Nahrungs- und Genussmittel aus dem Pflanzenreiche. Wien 1871.

†††) r. Höhnel: „Die Stärke and die Mahlproducte", Th. Fischer, Cassel and Berlin 1882. 